\title{
Study on Triopoly Dynamic Game Model Based on Different Demand Forecast Methods in the Market
}

\author{
Junhai Ma, ${ }^{1}$ Lijian Sun, ${ }^{1,2}$ and Xueli Zhan ${ }^{3}$ \\ ${ }^{1}$ College of Management and Economics, Tianjin University, Tianjin 300072, China \\ ${ }^{2}$ College of Science, Tianjin University of Science and Technology, Tianjin 300457, China \\ ${ }^{3}$ School of Economics, Beijing Wuzi University, Beijing 101149, China \\ Correspondence should be addressed to Junhai Ma; mjhtju@aliyun.com and Xueli Zhan; xuelz20163205@126.com
}

Received 11 February 2017; Revised 22 March 2017; Accepted 26 March 2017; Published 6 July 2017

Academic Editor: Christos Volos

Copyright (c) 2017 Junhai Ma et al. This is an open access article distributed under the Creative Commons Attribution License, which permits unrestricted use, distribution, and reproduction in any medium, provided the original work is properly cited.

\begin{abstract}
The impact of inaccurate demand beliefs on dynamics of a Triopoly game is studied. We suppose that all the players make their own estimations on possible demand with errors. A dynamic Triopoly game with such demand belief is set up. Based on this model, existence and local stable region of the equilibriums are investigated by $3 \mathrm{D}$ stable regions of Nash equilibrium point. The complex dynamics, such as bifurcation scenarios and route to chaos, are displayed in 2D bifurcation diagrams, in which $e_{1}$ and $\alpha$ are negatively related to each other. Basins of attraction are investigated and we found that the attraction domain becomes smaller with the increase in price modification speed, which indicates that all the players' output must be kept within a certain range so as to keep the system stable. Feedback control method is used to keep the system at an equilibrium state.
\end{abstract}

\section{Introduction}

A Triopoly is a market structure dominated by three firms in the market. The market is known as Cournot game if firms choose quantities as their strategic variables to maximize their profits in an uncertain demand environment.

In conventional market games, players are supposed to have common accurate demand functions of market. The dynamics of such system with this assumption have been intensively investigated in literature [1-8].

Assuming cost function to be twice differentiable increasing, Elabbasy et al. [1] analyzed the dynamics of oligopoly games with three types of players: bounded rational, naive, and adaptive.

$\mathrm{Ma}$ and Liu [2] studied a generalized nonlinear FokkerPlanck diffusion equation with external force and absorption. They obtained the corresponding exact solution expressed by $q$-exponential function and the solutions can have a compact behavior or a long tailed behavior.

Yassen and Agiza [3] studied a repeated Cournot game model with delayed bounded rationality in the duopoly market and demonstrated that the lagged structure is helpful to expand the stable region of the system via numerical simulations.

$\mathrm{Ma}$ and Ren [4] focused on the influence of parameters on the macroeconomics IS-LM model and improved the analysis capabilities of the traditional economic models to suit the actual macroeconomic environment. They found that the system order has an important influence on the running state of the system.

Tramontana and Elsadany [5] discussed a triopolistic market with heterogeneous firms when the demand function is isoelastic. He found that double routes lead to chaos, via period-doubling and Neimark-Sacker bifurcations.

Ma and Ji [6] built a Triopoly outputs game model in electric power market. They obtained that the Triopoly model is a chaotic system and it is better than the duopoly model in applications.

$\mathrm{Ma}$ and $\mathrm{Wu}$ [7] studied the complexity of a Triopoly price game model and influence of delayed decisions on the stability. All those approaches assume that there is one uniform and accurate market demand function available and shared by all player. 
$\mathrm{Ma}$ and $\mathrm{Pu}[8]$ researched the Cournot-Bertrand duopoly model with the application of nonlinear dynamics theory. They analyzed the stability of the fixed points and gave the bifurcation diagram and Lyapunov exponent spectrum along with the corresponding chaotic attractor. The research results show that either the change of output modification speed or the change of price modification speed will lead the market to the chaotic state which is disadvantageous for both of the firms.

All those literatures assume that there is one accurate market demand function, which is shared by all players. In practice, demand functions may be influenced by lots of different factors and every player has to estimate his own market demand function on the basis of past experience.

Because it is impossible for the firms to get the whole information, they cannot know the accurate demand function, so all the players have to make an estimate for demand function. Compared to real market demand function, it is inevitable for all the players to make demand evaluation biases. Thus, it is important to study how dynamics of the Triopoly game will be influenced by those evaluation biases, in terms of equilibrium points, local stability, and system performance.

A few works have been done to investigate the system dynamics, equilibrium offset with inaccurate demand beliefs. Bischi et al. [9] studied a model of a quantity-setting duopoly market with misspecified demand, the global dynamics of this game was investigated, and the number of steady states and their welfare properties were characterized. The impact of misspecified demand on the steady state was also studied. However, the asymmetric system with heterogeneous players' behavior has not been considered.

Wang and $\mathrm{Ma}[10]$ considered a Cournot-Bertrand mixed duopoly game model with limited information about the market and opponent. They studied the local stability of the game model at the Nash equilibrium point and discussed the influences of the parameters on the system's performance.

Bischi et al. [11] considered a repeated oligopoly game in single product Cournot oligopolies and proposed a method to learn demand function in a repeated oligopoly game via a closed loop feedback of real market price, which adjusts the evaluated demand function.

Guo and Ma [12] built a collecting price game model for a close-loop supply chain system with a manufacturer and a retailer who have different rationalities. They analyzed the influences of parameters on complex dynamic phenomena, such as the bifurcation, chaos, and continuous power spectrum.

Qiu et al. [13] studied the impact of uncertain demand on dynamic output-setting market games. A dynamic game with uncertain demand for two heterogeneous players was built. Based on this model, the impact of uncertain demand on the game's complex dynamics was investigated. Sun and Ma [14] constructed the three-oligopoly game model and investigated the existence of the fixed points. The 3D stable regions were given. The complex dynamic behavior of the game model is studied and the chaos was successfully controlled.
In this paper, we analyze the complex dynamics of a Triopoly model with heterogeneous players and demand evaluation bias, focusing on the following perspectives:

(1) Impact of demand estimate bias on equilibrium, stable region, and profits.

(2) Impact of adjustment strategy on basins of attraction.

The paper is organized as follows. In Section 2, a Triopoly game model with inaccurate demand belief is established. In Section 3, the existence and local stability of equilibrium points are discussed. The effects of inaccurate demand on stable region, profit, and equilibriums are shown in Section 4 . Dynamical behaviors of the game are investigated by numerical simulations using 2D bifurcation diagrams [15] in Section 5. Basins of attraction [16] of the model are given in Section 7. In Section 8, conclusions are drawn from our analysis.

\section{The Cournot Triopoly Game Model}

We consider a Cournot Triopoly game in which the price and the demand of firm $i$ 's product are denoted by $p_{i}$ and $q_{i}, i=$ $1,2,3$, and the demand functions for the three firms are as follows:

$$
p=a-b\left(q_{1}+q_{2}+q_{3}\right)
$$

in which $a$ and $b$ are both positive constants. Assume that all the three firms have nonlinear cost function considering that if $q_{i}$ exceeds a certain level, the cost will increase quickly and the cost function of the $i$ th firm has a quadratic form [3]:

$$
C_{i}\left(q_{i}\right)=c_{i} q_{i}^{2} \quad(i=1,2,3) .
$$

While in practice, not all the firms can get the whole information, they may do not know demand function (1), so all the players have to make an estimate for demand function.

For each player, we assume that the actual demand function held by player $i$ can be denoted by multiplying the demand function (1) with an error coefficient $e_{i}$. And it has the following form:

$$
p=e_{i}\left(a-b\left(q_{1}+q_{2}+q_{3}\right)\right)
$$

which is called its subjective demand function.

The error coefficient $e_{i}$ which is between $(0,3)$ means the imperfection degree of player $i$ about the market.

If $e_{i}=1$, it indicates that the evaluated demand function is just the true demand function. If $e_{i}<1$, it indicates that the demand is underestimated by player, while if $e_{i}>1$, it indicates the case where the demand is overestimated.

So the firms can get their maximum profits according to the following profit functions:

$$
\begin{aligned}
& \pi_{1}(t)=e_{1}\left(a-b\left(q_{1}+q_{2}+q_{3}\right)\right) q_{1}-c_{1} q_{1}^{2} \\
& \pi_{2}(t)=e_{2}\left(a-b\left(q_{1}+q_{2}+q_{3}\right)\right) q_{2}-c_{2} q_{2}^{2} \\
& \pi_{3}(t)=e_{3}\left(a-b\left(q_{1}+q_{2}+q_{3}\right)\right) q_{3}-c_{3} q_{3}^{2},
\end{aligned}
$$


in which $\pi_{i}(t)$ is the profit of firm $i$. Hence, the marginal profit functions of firms in period $t$ are given by

$$
\begin{aligned}
& \frac{\partial \pi_{1}(t)}{\partial q_{1}(t)}=e_{1}\left(a-2 b q_{1}(t)-b\left(q_{2}(t)+q_{3}(t)\right)\right)-2 c_{1} q_{1} \\
& \frac{\partial \pi_{2}(t)}{\partial q_{2}(t)}=e_{2}\left(a-2 b q_{2}(t)-b\left(q_{1}(t)+q_{3}(t)\right)\right)-2 c_{2} q_{2} \\
& \frac{\partial \pi_{3}(t)}{\partial q_{3}(t)}=e_{3}\left(a-2 b q_{3}(t)-b\left(q_{2}(t)+q_{1}(t)\right)\right)-2 c_{3} q_{3},
\end{aligned}
$$

while in practice, firms usually cannot get the whole information. For example, they cannot know other firm's price in the next period in advance, for which they cannot compute the price by the marginal profit functions above. In this paper, we consider all the firms as bounded rational players and their next-period price decisions are made on the basis of the local estimate to their marginal profit in current period. So the players make their strategies as the following form:

$$
q_{i}(t+1)=q_{i}(t)+k_{i} q_{i}(t) \frac{\partial \pi_{i}(t)}{\partial q_{i}(t)} \quad\left(k_{i}=\alpha, \beta, \gamma\right) .
$$

The equation means that if the marginal profit of the current period is positive, the firm will raise its price the next period; otherwise, it will reduce it. So the dynamical Triopoly system can be described as

$$
\begin{aligned}
& q_{1}(t+1)=q_{1}(t)+\alpha q_{1}(t) G_{1}(t) \\
& q_{2}(t+1)=q_{2}(t)+\beta q_{2}(t) G_{2}(t) \\
& q_{3}(t+1)=q_{3}(t)+\gamma q_{3}(t) G_{3}(t),
\end{aligned}
$$

where

$$
\begin{aligned}
& G_{1}(t)=e_{1}\left(a-2 b q_{1}(t)-b\left(q_{2}(t)+q_{3}(t)\right)\right)-2 c_{1} q_{1} \\
& G_{2}(t)=e_{2}\left(a-2 b q_{2}(t)-b\left(q_{1}(t)+q_{3}(t)\right)\right)-2 c_{2} q_{2} \\
& G_{3}(t)=e_{3}\left(a-2 b q_{3}(t)-b\left(q_{2}(t)+q_{1}(t)\right)\right)-2 c_{3} q_{3} .
\end{aligned}
$$

$0<\alpha, \beta, \gamma<1$ denote the players' adjustment speeds, respectively.

\section{Equilibrium Points and Local Stability}

3.1. Equilibrium Points. According to system (7), let $p_{i}(t+1)=$ $p_{i}(t)$; then eight equilibrium points can be obtained:

$$
\begin{aligned}
E_{1} & =(0,0,0) \\
E_{2} & =\left(0, \frac{a e_{2}}{\left(2\left(c_{2}+b e_{2}\right)\right)}, 0\right) \\
E_{3} & =\left(\frac{a e_{1}}{\left(2\left(c_{1}+b e_{1}\right)\right)}, 0,0\right) \\
E_{4} & =\left(0,0, \frac{a e_{3}}{\left(2\left(c_{3}+b e_{3}\right)\right)}\right) \\
E_{5} & =\left(0, \frac{a e_{2}\left(2 c_{3}+b e_{3}\right)}{\left(4 c_{2} c_{3}+4 b c_{2} e_{3}+4 b c_{3} w_{2}+3 b^{2} e_{2} e_{3}\right)},\right. \\
& \left.\frac{a e_{3}\left(2 c_{2}+b e_{2}\right)}{\left(4 c_{2} c_{3}+4 b c_{2} e_{3}+4 b c_{3} e_{2}+3 b^{2} e_{2} e_{3}\right)}\right) \\
E_{6} & =\left(\frac{a e_{1}\left(2 c_{2}+b e_{2}\right)}{\left(4 c_{2} c_{1}+4 b c_{1} e_{2}+4 b c_{2} e_{1}+3 b^{2} e_{2} e_{1}\right)},\right. \\
E_{7} & =\left(\frac{a e_{3}\left(2 c_{1}+b e_{1}\right)}{\left(4 c_{3} c_{1}+4 b c_{1} e_{3}+4 b c_{3} e_{1}+3 c^{2} e_{3} e_{1}\right)}, 0,\right. \\
& \left.\frac{\left.a c_{1} e_{3}+4 b c_{3} e_{1}+3 b^{2} e_{3} e_{1}\right)}{\left(4 c_{2} c_{1}+4 b c_{1} e_{2}+4 b c_{2} e_{1}+3 b^{2} e_{2} e_{1}\right)}, 0\right) \\
& \left(2 c_{3}+b e_{3}\right)
\end{aligned}
$$

and the Nash equilibrium point

$$
E_{8}=\left(q_{1}^{*}, q_{2}^{*}, q_{3}^{*}\right)
$$

can be obtained, where

$$
\begin{aligned}
& q_{1}^{*}=\frac{\left(4 a c_{2} c_{3} e_{1}+2 a b c_{2} e_{1} e_{3}+2 a b c_{3} e_{1} e_{2}+a b^{2} e_{1} e_{2} e_{3}\right)}{\left(2\left(4 c_{1} c_{2} c_{3}+3 b^{2} c_{1} e_{2} e_{3}+3 b^{2} c_{2} e_{1} e_{3}+3 b^{2} c_{3} e_{1} e_{2}+2 b^{3} e_{1} e_{2} e_{3}+4 b c_{1} c_{2} e_{3}+4 b c_{1} c_{3} e_{2}+4 b c_{2} c_{3} e_{1}\right)\right)} \\
& q_{2}^{*}=\frac{\left(a e_{2}\left(2 c_{1}+b e_{1}\right)\left(2 c_{3}+b e_{3}\right)\right)}{\left(2\left(4 c_{1} c_{2} c_{3}+3 b^{2} c_{1} e_{2} e_{3}+3 b^{2} c_{2} e_{1} e_{3}+3 b^{2} c_{3} e_{1} e_{2}+2 b^{3} e_{1} e_{2} e_{3}+4 b c_{1} c_{2} e_{3}+4 b c_{1} c_{3} e_{2}+4 b c_{2} c_{3} e_{1}\right)\right)} \\
& q_{3}^{*}=\frac{\left(a e_{3}\left(2 c_{1}+b e_{1}\right)\left(2 c_{2}+b e_{2}\right)\right)}{\left(2\left(4 c_{1} c_{2} c_{3}+3 b^{2} c_{1} e_{2} e_{3}+3 b^{2} c_{2} e_{1} e_{3}+3 b^{2} c_{3} e_{1} e_{2}+2 b^{3} e_{1} e_{2} e_{3}+4 b c_{1} c_{2} e_{3}+4 b c_{1} c_{3} e_{2}+4 b c_{2} c_{3} e_{1}\right)\right)} .
\end{aligned}
$$

It can be seen from above that $E_{8}$ is independent of the adjustment factors. From an economic point of view, that means the value of the system local stability point in this dynamic game is independent of the players' adjustment speed, but just 
determined by the characteristics of the system. We can find from (11) that if $e_{i}$ of player $i$ increases and $e_{j}$ of other players remains the same, $q_{i}^{*}$ will increase.
3.2. Nash Points in Error-Free System-Benchmark. If the players have perfect knowledge, their subjective demand functions totally coincide with the real ones. Setting $e_{1}=e_{2}=$ $e_{3}=1$ in (11), we can get

$$
\begin{aligned}
& q_{1}^{*}=\frac{a\left(b+2 c_{2}\right)\left(b+2 c_{3}\right)}{\left(6 b^{2} c_{1}+6 b^{2} c_{2}+6 b^{2} c_{3}+4 b^{3}+8 b c_{1} c_{2}+8 b c_{1} c_{3}+8 b c_{3} c_{2}+8 c_{1} c_{2} c_{3}\right)} \\
& q_{2}^{*}=\frac{a\left(b+2 c_{1}\right)\left(b+2 c_{3}\right)}{\left(6 b^{2} c_{1}+6 b^{2} c_{2}+6 b^{2} c_{3}+4 b^{3}+8 b c_{1} c_{2}+8 b c_{1} c_{3}+8 b c_{3} c_{2}+8 c_{1} c_{2} c_{3}\right)} \\
& q_{3}^{*}=\frac{a\left(b+2 c_{1}\right)\left(b+2 c_{2}\right)}{\left(6 b^{2} c_{1}+6 b^{2} c_{2}+6 b^{2} c_{3}+4 b^{3}+8 b c_{1} c_{2}+8 b c_{1} c_{3}+8 b c_{3} c_{2}+8 c_{1} c_{2} c_{3}\right)} .
\end{aligned}
$$

Note that the denominator of $q_{1}^{*}, q_{2}^{*}$, and $q_{3}^{*}$ is the same, the output depends on the cost of the players, and the greater the cost, the lower the yield. These results match the results in [17].

3.3. Local Stability of System Equilibriums. In order to analyze the stability of the preceding equilibrium points, the Jacobian matrix for discrete dynamic system (7) is found as follows:

$$
J=\left(\begin{array}{ccc}
J_{1} & -\alpha b e_{1} q_{1} & -\alpha b e_{1} q_{1} \\
-\beta b e_{2} q_{2} & J_{2} & -\beta b e_{2} q_{2} \\
-\gamma b e_{3} q_{3} & -\gamma b e_{3} q_{3} & J_{3}
\end{array}\right)
$$

in which

$$
\begin{aligned}
J_{1}= & 1-\alpha q_{1}\left(2 c_{1}+2 b e_{1}\right) \\
& -\alpha\left(e_{1}\left(b\left(q_{2}+q_{3}\right)-a+2 b q_{1}\right)+2 c_{1} q_{1}\right) \\
J_{2}= & -\beta q_{2}\left(2 c_{2}+2 b e_{2}\right) \\
& -\beta\left(e_{2}\left(b\left(q_{1}+q_{3}\right)-a+2 b q_{2}\right)+2 c_{2} q_{2}\right) \\
J_{3}= & -\gamma q_{3}\left(2 c_{3}+2 b e_{3}\right) \\
& -\gamma\left(e_{3}\left(b\left(q_{1}+q_{2}\right)-a+2 b q_{3}\right)+2 c_{3} q_{3}\right) .
\end{aligned}
$$

According to Routh-Hurwitz condition, the necessary and sufficient conditions for equilibrium points to be asymptotically stable are that all roots of the characteristic equations have magnitudes of eigenvalues less than 1 .

Remark 1. $E_{1}, E_{2}, E_{3}, E_{4}$ are unstable equilibrium points.

As for $E_{1}, J_{1}=1+a \alpha>1$ is one eigenvalue which corresponds to $E_{1}$, so $E_{1}$ is an unstable equilibrium point.

As for $E_{2}, J_{1}=1+\alpha e_{1} a\left(1-b e_{2} /\left(2 c_{2}+2 b e_{2}\right)\right)>1$ is one eigenvalue which corresponds to $E_{2}$, so $E_{2}$ is an unstable equilibrium point. In the same way we can prove that $E_{3}$ and $E_{4}$ are unstable equilibrium points.

Remark 2. $E_{5}, E_{6}$, and $E_{7}$ are unstable equilibrium points.

As for $E_{5}, J_{1}=1-\alpha\left(e_{1}\left(b\left(q_{2}+q_{3}\right)-a\right)\right)$ is one eigenvalue which corresponds to $E_{1}$; set $q_{2}=a e_{2}\left(2 c_{3}+b e_{3}\right) /\left(4 c_{2} c_{3}+\right.$ $\left.4 b c_{2} e_{3}+4 b c_{3} e_{2}+3 b^{2} e_{2} e_{3}\right), q_{3}=a e_{3}\left(2 c_{2}+b e_{2}\right) /\left(4 c_{2} c_{3}+\right.$ $\left.4 b c_{2} e_{3}+4 b c_{3} e_{2}+3 b^{2} e_{2} e_{3}\right)$, and then $b\left(q_{2}+q_{3}\right)-a<0$, so $J_{1}=1-\alpha\left(e_{1}\left(b\left(q_{2}+q_{3}\right)-a\right)\right)>1$.

So $E_{5}$ is an unstable equilibrium point. In the same way we can prove that $E_{6}$ and $E_{7}$ are unstable equilibrium points.

From an economic point of view, in the stable state of this dynamic game, no player is forced to withdraw from the market.

As for $E_{8}$, the necessary and sufficient condition of asymptotic stability is that all the eigenvalues are inside the unit circle in complex plane. So a stable system must satisfy the following conditions:

$$
\begin{aligned}
f(1) & =1+A+B+C>0 \\
-f(-1) & =1-A+B-C>0 \\
C^{2}-1 & <0 \\
\left(1-C^{2}\right)^{2}-(B-A C)^{2} & >0,
\end{aligned}
$$

where $f(\lambda)=\lambda^{3}+A \lambda^{2}+B \lambda+C=0$ is the characteristic polynomial at $E_{8}$.

For convenience, we set the parameters as follows:

$$
\begin{aligned}
& a=10, \\
& b=0.2, \\
& c_{1}=0.1, \\
& c_{2}=0.1, \\
& c_{3}=0.1, \\
& e_{1}=0.9, \\
& e_{2}=1.0 ; \\
& e_{3}=1.1 ;
\end{aligned}
$$

and the initial values are chosen as $(1,1,1)$.

According to the parameters above,

$$
E_{8}=(9.4832,10.0100,10.4867) .
$$




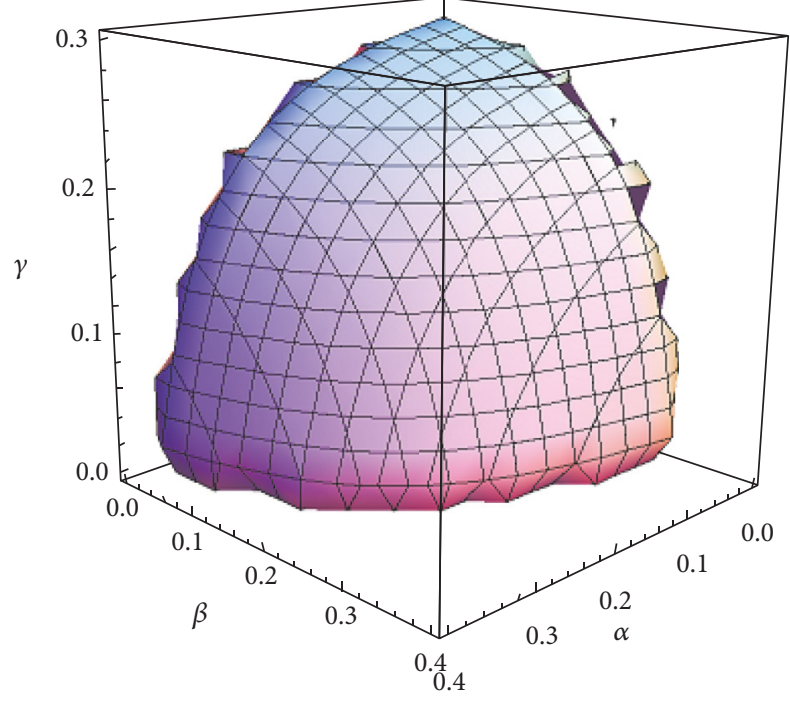

FIgURE 1: The stable region of Nash equilibrium point, $\left(e_{1}, e_{2}, e_{3}\right)=$ $(0.9,1.0,1.1)$.

Its Jacobian matrix is

$$
J\left(E_{8}\right)=\left(\begin{array}{ccc}
1.0-5.31 \alpha & -1.71 \alpha & -1.71 \alpha \\
-2.0 \beta & 1.0-6.01 \beta & -2.0 \beta \\
-2.31 \gamma & -2.31 \gamma & 1.0-6.71 \gamma
\end{array}\right)
$$

The characteristic equation of Jacobian matrix (18) is

$$
f(\lambda)=\lambda^{3}+A_{1} \lambda^{2}+B_{1} \lambda+C_{1}=0
$$

in which

$$
\begin{aligned}
A_{1} & =(5.31 \alpha+6.01 \beta+6.71 \gamma-3.0) \\
B_{1} & =((6.71 \gamma-1.0)(5.31 \alpha+6.01 \beta-2.0)-3.42 \alpha \beta \\
& -3.94 \alpha \gamma-4.62 \beta \gamma+(5.31 \alpha-1.0)(6.01 \beta-1.0)) \\
C_{1} & =2.31 \gamma(3.42 \alpha \beta+1.71 \alpha(5.31 \alpha-1.0))-(3.94 \alpha \gamma \\
& +4.62 \beta \gamma)(5.31 \alpha+6.01 \beta-2.0)-(6.71 \gamma-1.0) \\
& \cdot(3.42 \alpha \beta-(5.31 \alpha-1.0)(6.01 \beta-1.0)) \\
& +2.31 \gamma(2.0 \beta(6.01 \beta-1.0)+3.42 \alpha \beta) .
\end{aligned}
$$

As what can be shown in Figure 1, a stable region in the space of $(\alpha, \beta, \gamma)$ is determined by the above inequalities. In the stable region, the final prices of the three oligarchs will stay stable at $E_{8}$ after a number of games. From Figure 1, we can see that the market is stable when $v \in[0,1]$, but the market may be unstable when $\alpha, \beta, \gamma$ increases. The economic meaning of the stable region is that if $(\alpha, \beta, \gamma)$ is in the stable region, prices of three firms will achieve the Nash equilibrium at last.

3.4. The Effects of Parameters $e_{i}$ on Stable Region. In order to analyze the effects of parameter $w$ on stable region, let

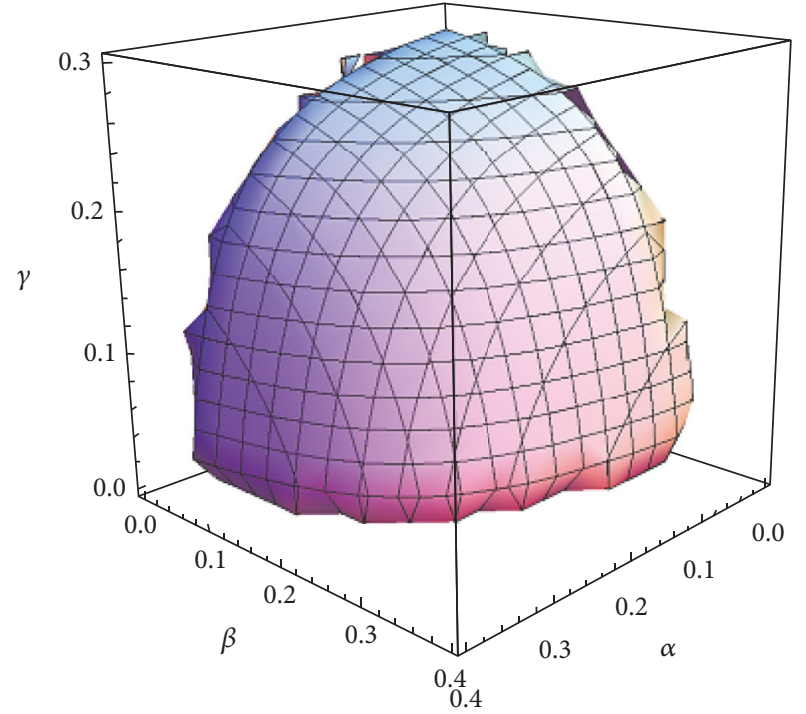

FIgURE 2: The stable region of Nash equilibrium point, $\left(e_{1}, e_{2}, e_{3}\right)=$ $(1,1.1,1.2)$.

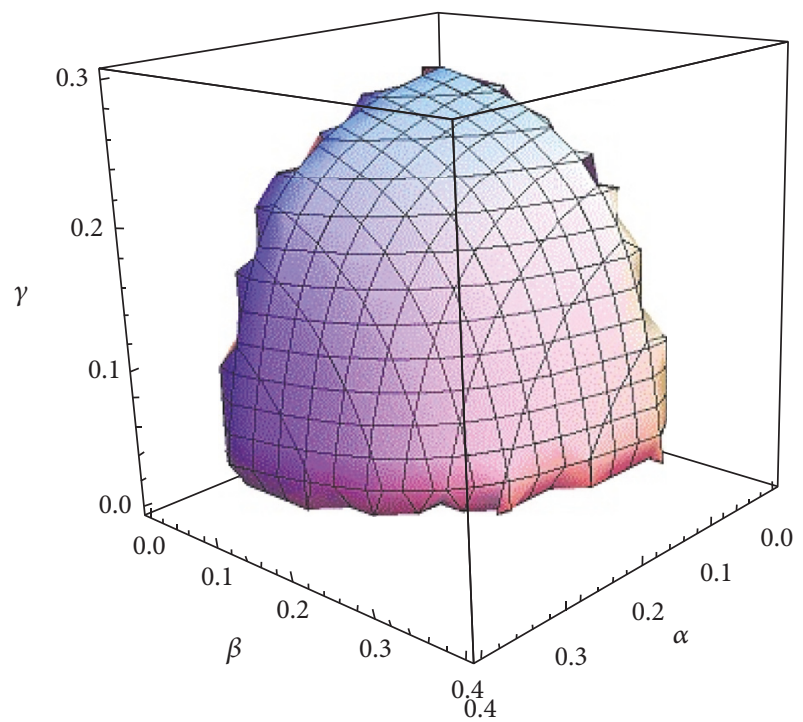

FIgURE 3: The stable region of Nash equilibrium point, $\left(e_{1}, e_{2}, e_{3}\right)=$ $(0.8,0.9,1)$.

$\left(e_{1}, e_{2}, e_{3}\right)=(1,1.1,1.2)$ and $(0.8,0.9,1)$, respectively; then the corresponding stable region is shown in Figures 2 and 3. From the comparison we find that, with the increase of $e_{i}$, the stable region narrows.

From an economic point of view, if the players overestimate the demand, the range of price adjustment speed will be smaller; however if the players underestimate the demand, the range of price adjustment speed will be bigger.

\section{Bifurcation Diagrams}

4.1. $2 D$ Bifurcation Diagrams and Interactive Relationships between $e_{1}$ and $\alpha, \beta$, and $\gamma$. 2D bifurcation diagram is a more powerful tool in the numerical analysis of nonlinear 


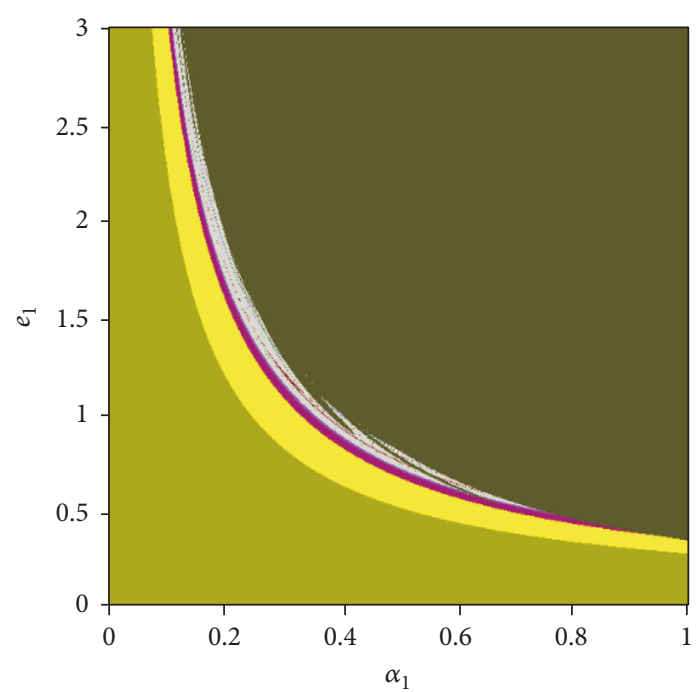

FIgURE 4: $\left(e_{1}, \alpha\right)$-2D bifurcation diagram with $\beta=0.2$ and $\gamma=0.1$.

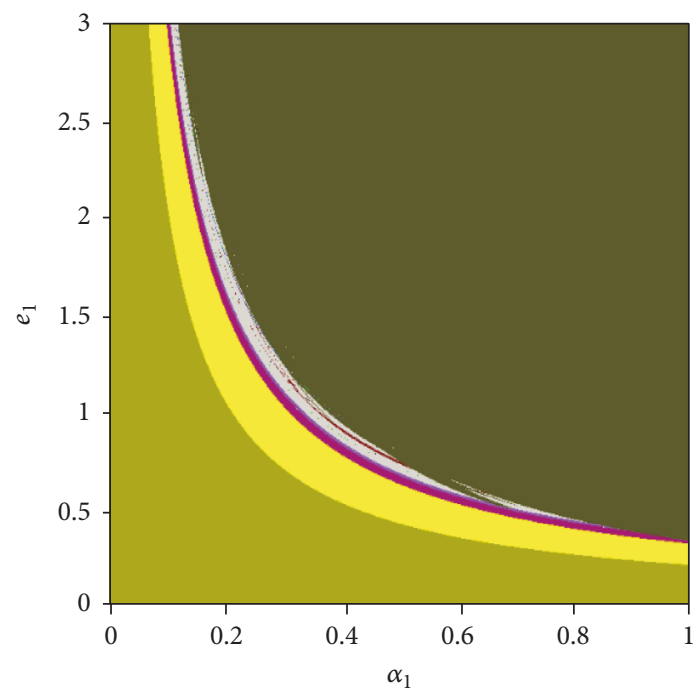

FIgURE 5: $\left(e_{1}, \alpha\right)$-2D bifurcation diagram with $\beta=0.25$ and $\gamma=0.1$.

dynamics than a $1 \mathrm{D}$ bifurcation diagram. In the $2 \mathrm{D}$ bifurcation diagram, bifurcation scenarios and route to chaos can be displayed more clearly. In this section, the $2 \mathrm{D}$ bifurcation diagram will be used to analyze the effects of players' adjustment speeds and $e_{1}$ on system stability.

For convenience, we choose $e_{2}=1$ and $e_{3}=1.1$ and study the interactive relationships between $e_{1}$ and $\alpha$ by $2 \mathrm{D}$ bifurcation diagrams.

First let $\gamma=0.1$ and $\beta=0.2,0.25,0.3$, respectively; then three $(\alpha, e 1) 2 \mathrm{D}$ bifurcation diagrams are shown in Figures 4, 5 , and 6 .

In Figures 4-6, different colors are assigned to each region to show the particular behavior of system (7), that is, light green, stable states; yellow, period-2 stable cycles; purple, period-4; gray, chaotic state; dark green, escape.

In the $2 \mathrm{D}$ bifurcation diagrams, the system exhibits a sequence of flip bifurcations to chaos (which means that the

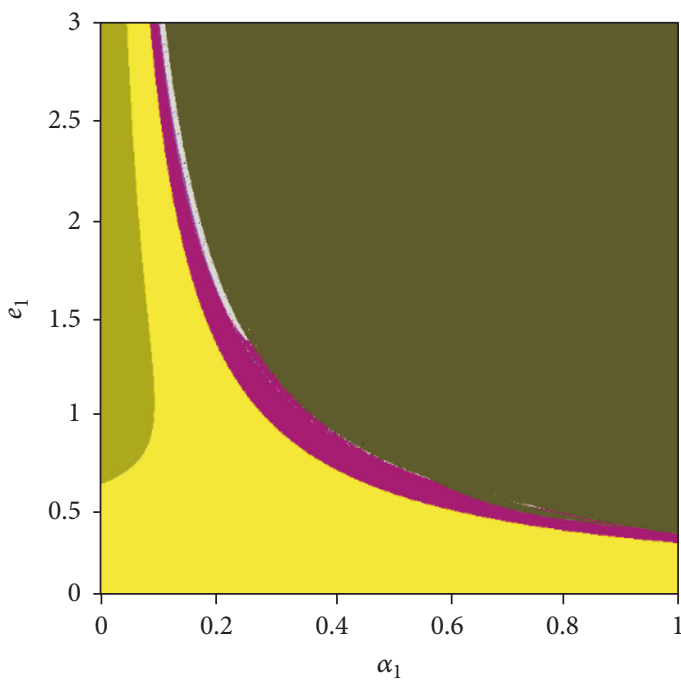

FIgURE 6: $\left(e_{1}, \alpha\right)$-2D bifurcation diagram with $\beta=0.3$ and $\gamma=0.1$.

market will fall into chaos), then to divergence at last (which means the players will be out of the market).

As seen from Figure 4, if player 1's adjustment speed is relatively slow (in the brown area), the economic system will be in a stable state. Along with the increase in the adjustment speed parameters, the economic system will experience cyclical shocks, chaos, and even disappearance. Obviously, relatively large parameters are detrimental to the economic system.

We can find the following results from Figures 4, 5, and 6,

(1) We find that, in the stable region in every figure, with the increase in $\alpha$, the maximum of $e_{1}$ decreases; with the increase in $e_{1}$, the maximum of $\alpha$ decreases.

(2) We find that, with the increase in $\beta$, stable region reduces, while escape region does not expand obviously, but period-2 stable cycles expand obviously.

Secondly fix $\beta$ at 0.1 , let $\gamma=0.2,0.25,0.3$, respectively, and then three $\left(\alpha, e_{1}\right) 2 \mathrm{D}$ bifurcation diagrams can be shown in Figures 7, 8, and 9. Comparing Figures 7, 8, and 9, we find that, with the increasing of $\gamma$, stable region reduces, while escape region does not expand obviously, but period-2 stable cycles and period- 4 stable cycles expand obviously, from the comparison of Figures 7, 8, and 9, stable region of player 1 reduces when $\beta$ and $\gamma$ increase.

Let $\beta=0.2$ and $\gamma=0.2$, and then we can get Figure 10 .

Comparing Figures 4 and 10 , we can find that $\beta$ and $\gamma$ are nearly symmetrical and any parameter $(\beta$ and $\gamma)$ of changes will make stable region smaller.

4.2. 1D Bifurcation Diagrams and Interactive Attractors. We will display the consistency between $1 \mathrm{D}$ bifurcation diagrams and $2 \mathrm{D}$ bifurcation diagrams for Figure 10 and show the attractors.

In Figure $10, \beta=0.2$ and $\gamma=0.2$; if $e_{1}$ is fixed at 0.9, then we can get the bifurcation diagrams with $\alpha$ in Figure 11, in which blue set of points denotes $p_{1}(t)$, red set of points 


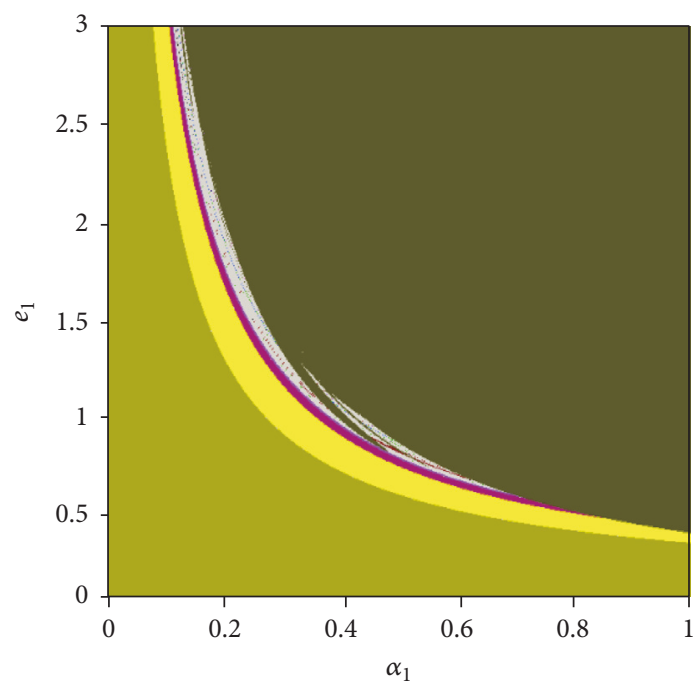

FIgURE 7: $\left(e_{1}, \alpha\right)$-2D bifurcation diagram with $\beta=0.1$ and $\gamma=0.2$.

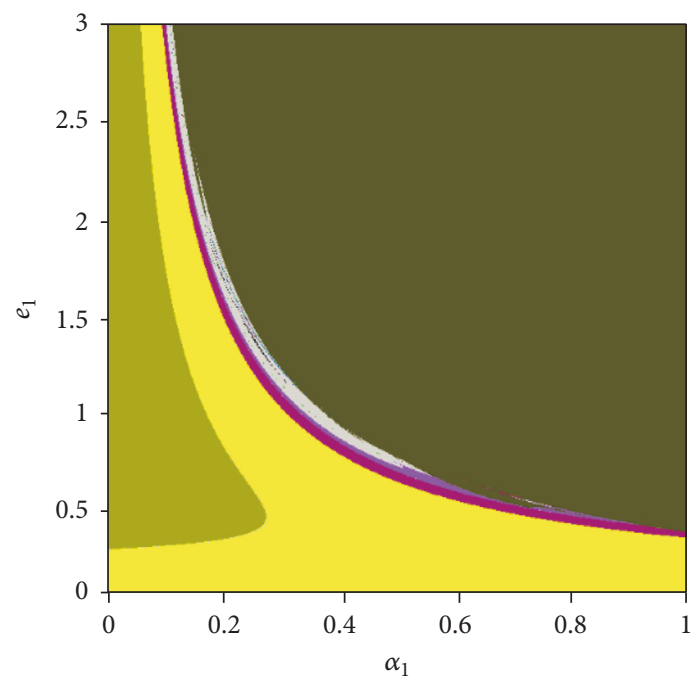

FIGURE 8: $\left(e_{1}, \alpha\right)$-2D bifurcation diagram with $\beta=0.1$ and $\gamma=0.25$.

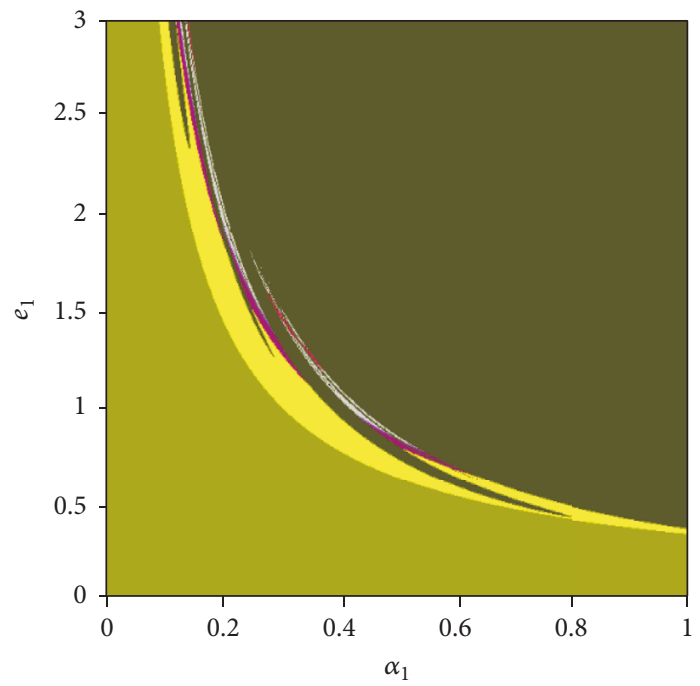

FIGURE 9: $\left(e_{1}, \alpha\right)$-2D bifurcation diagram with $\beta=0.1$ and $\gamma=0.3$.

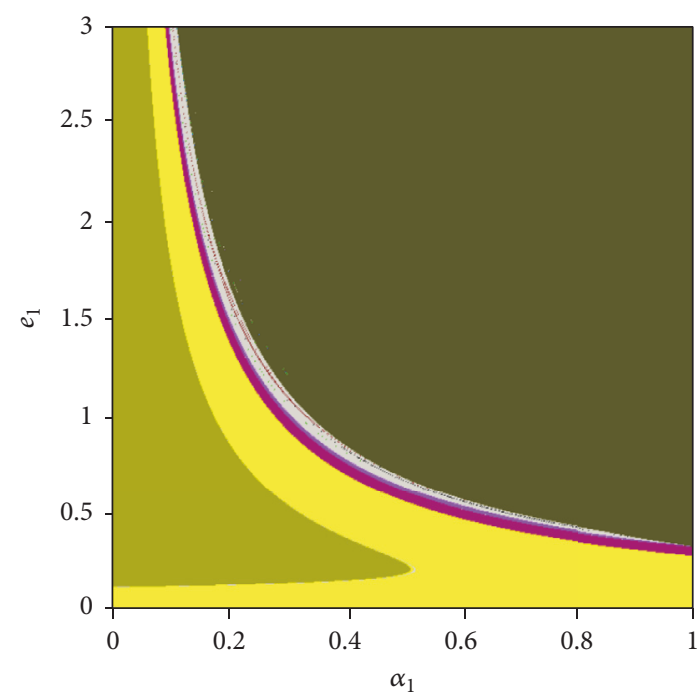

FigURE 10: $\left(e_{1}, \alpha\right)$-2D bifurcation diagram with $\beta=0.2$ and $\gamma=0.2$.

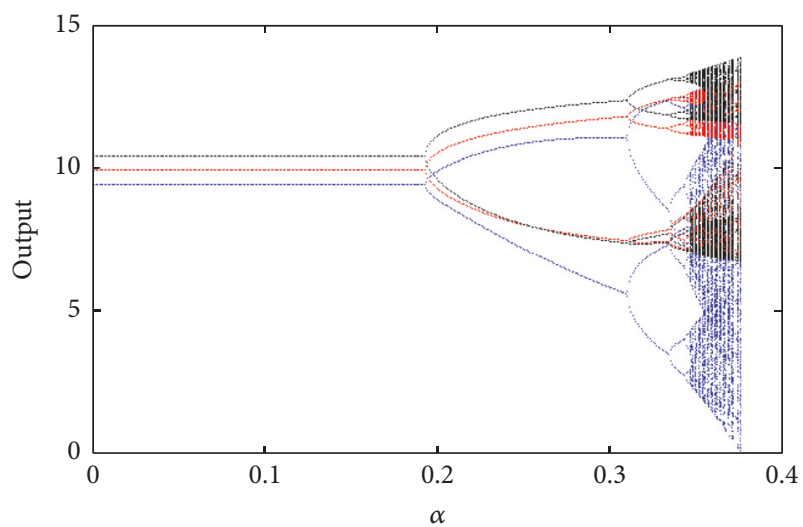

Figure 11: Bifurcation diagram with $\alpha, \beta=0.2$ and $\gamma=0.2$.

denotes $p_{2}(t)$, and black set of points denotes $p_{3}(t)$. As can be seen, system (7) loses its stability when $\alpha=0.2$, and after a series of flip bifurcations, it falls into chaos when $\alpha=$ 0.36 , which is consistent with Figure 10 . We can find that, with the same cost, the player $i$ with bigger $e_{i}$ has a higher equilibrium output, and player $i$ with smaller $e_{i}$ has a lower equilibrium output. We also give the corresponding largest Lyapunov exponent (LLE), which is consistent with Figure 12.

According to Figure 8, when $\alpha=0.3$ and $\beta=0.6$, LLE is positive, then system (7) is in chaos, and the chaotic attractor is shown in Figure 13.

From an economic point of view, the appearance of flip bifurcation means market gradually going into the chaotic state from the constant and violent fluctuations.

Under certain conditions, higher $e_{1}$ can improve the equilibrium result, as shown in Figure 11. However, it is not to say that the increase in $e_{1}$ will certainly increase the equilibrium output, if $e_{1}$ goes beyond the stability region. Increase in $e_{1}$ may lead to fluctuations in the system and not necessarily can play a role in improving production, which 


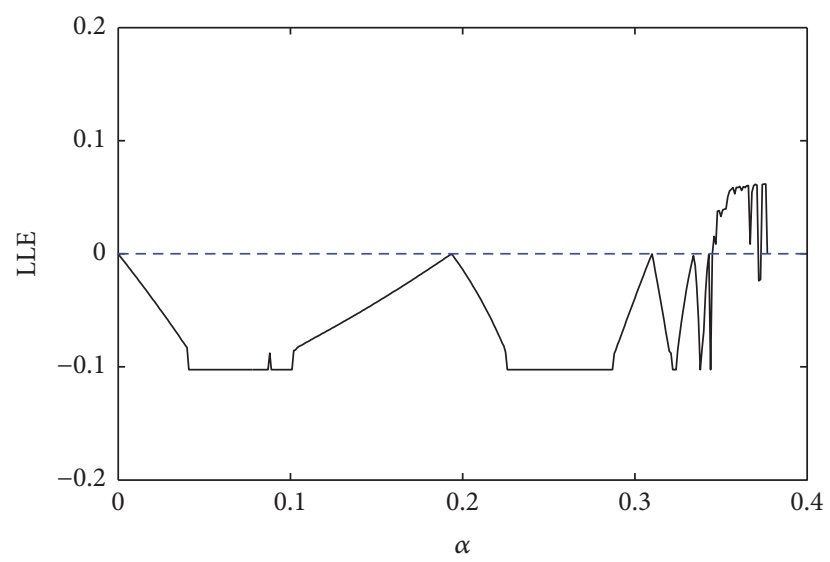

FIGURE 12: Largest Lyapunov exponent with $\alpha, \beta=0.2$ and $\gamma=0.2$.

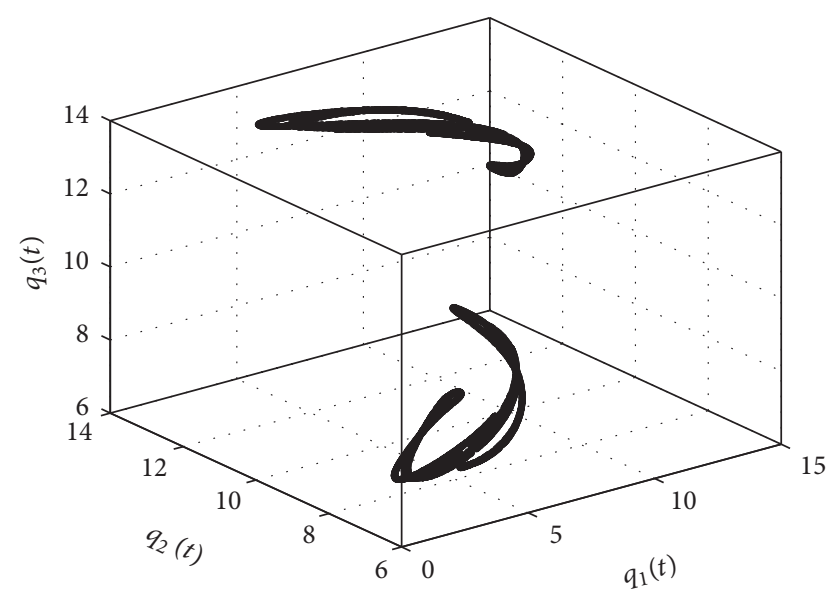

FIGURE 13: The chaotic attractor of system (7) with $\alpha=0.36, \beta=0.2$, and $\gamma=0.2$.

can be seen in Figures 14, 15, and 16. We also find that the increase in $e_{1}$ will decrease output of other players.

\section{The Effects of $e_{i}$ on Profits}

Next we will discuss the effects of $e_{i}$ on profits; merge (4)-(7):

$$
\begin{gathered}
q_{1}(t+1)=q_{1}(t)+\alpha q_{1}(t) \\
{\left[e_{1}\left(a-2 b q_{1}(t)-b\left(q_{2}(t)+q_{3}(t)\right)\right)-2 c_{1} q_{1}\right]} \\
q_{2}(t+1)=q_{2}(t)+\beta q_{2}(t) \\
{\left[e_{2}\left(a-2 b q_{2}(t)-b\left(q_{1}(t)+q_{3}(t)\right)\right)-2 c_{2} q_{2}\right]} \\
q_{3}(t+1)=q_{3}(t)+\gamma q_{3}(t) \\
{\left[e_{3}\left(a-2 b q_{3}(t)-b\left(q_{2}(t)+q_{1}(t)\right)\right)-2 c_{3} q_{3}\right]} \\
\pi_{1}(t)=e_{1}\left(a-b\left(q_{1}+q_{2}+q_{3}\right)\right) q_{1}-c_{1} q_{1}^{2} \\
\pi_{2}(t)=e_{2}\left(a-b\left(q_{1}+q_{2}+q_{3}\right)\right) q_{2}-c_{2} q_{2}^{2} \\
\pi_{3}(t)=e_{3}\left(a-b\left(q_{1}+q_{2}+q_{3}\right)\right) q_{3}-c_{3} q_{3}^{2} .
\end{gathered}
$$

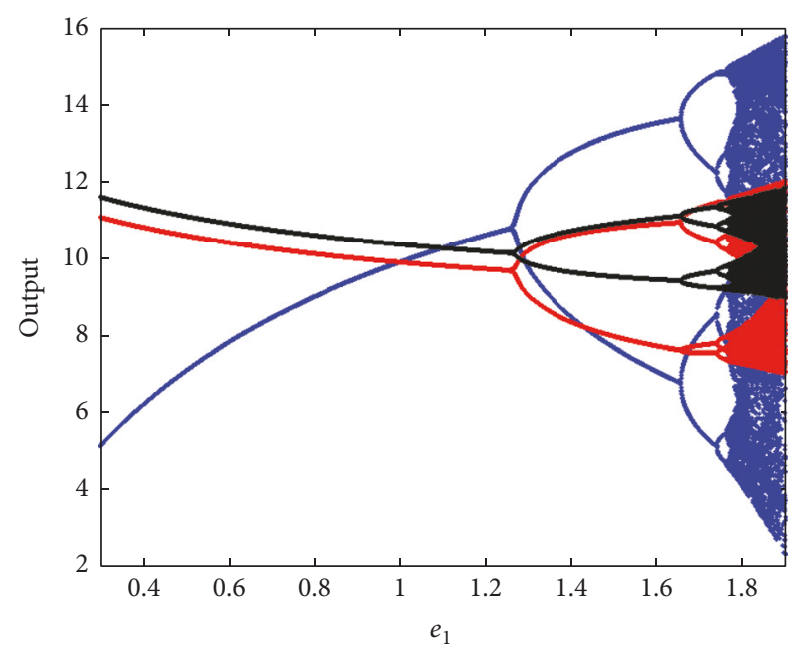

FIGURE 14: Bifurcation diagram with $e_{1}, \alpha=0.2, \beta=0.2$, and $\gamma=$ 0.1 .

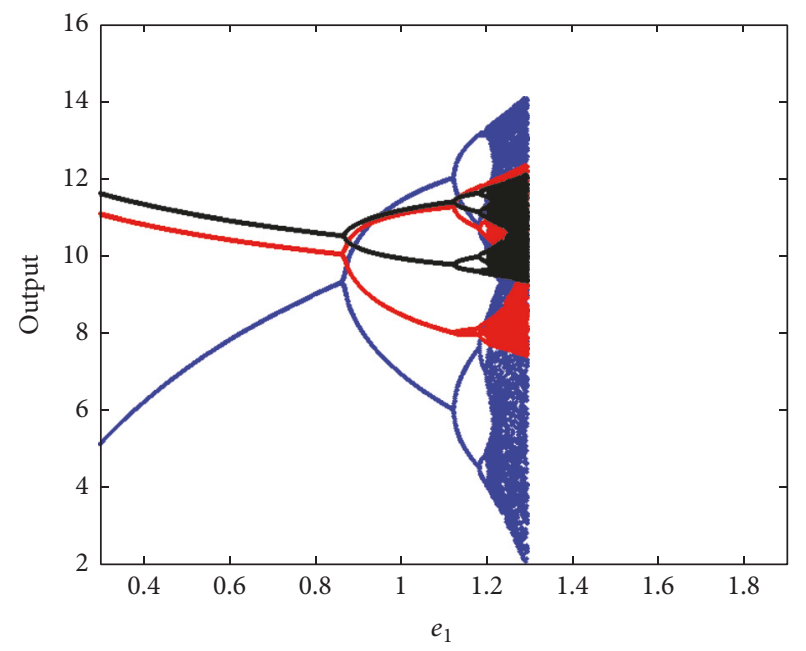

FIGURE 15: Bifurcation diagram with $e_{1}, \alpha=0.3, \beta=0.2$, and $\gamma=$ 0.1 .

The effects of $e_{1}$ on the three firms' profits can be shown in Figures 17-19.

The values of the parameters are the same as above, blue set of points denotes $\pi_{1}(t)$, red set of points denotes $\pi_{2}(t)$, and black set of points denotes $\pi_{3}(t)$.

We can conclude from Figure 17 that if $e_{1}<1.3$, with increase of $e_{1}, \pi_{1}(t)$ increases, $\pi_{2}(t)$ and $\pi_{3}(t)$ decrease; when $e_{1}>1.3$, all the firms' profits will lose stability and even fall into chaos. Comparing Figures 15 and 16, we can get Figures 18 and 19.

When the speed of adjustment is accelerated, increase of $e_{1}$ may cause the system to lose stability, not necessarily to improve the profit.

An interesting phenomenon is that, compared with bifurcation diagram with $e_{1}$, fluctuations in profits are smaller than fluctuations in output. 


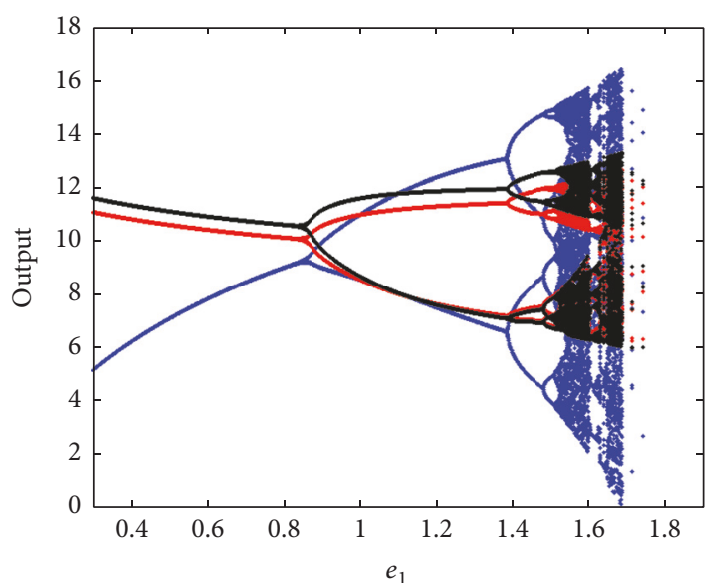

FIGURE 16: Bifurcation diagram with $e_{1}, \alpha=0.2, \beta=0.2$, and $\gamma=$ 0.2 .

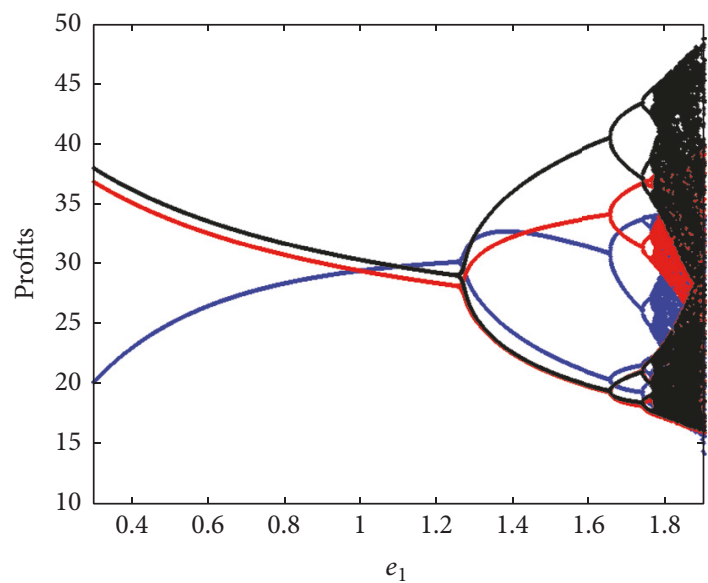

FIGURE 17: Effects of $e_{1}$ on profits, $\alpha=0.2, \beta=0.2$, and $\gamma=0.1$.

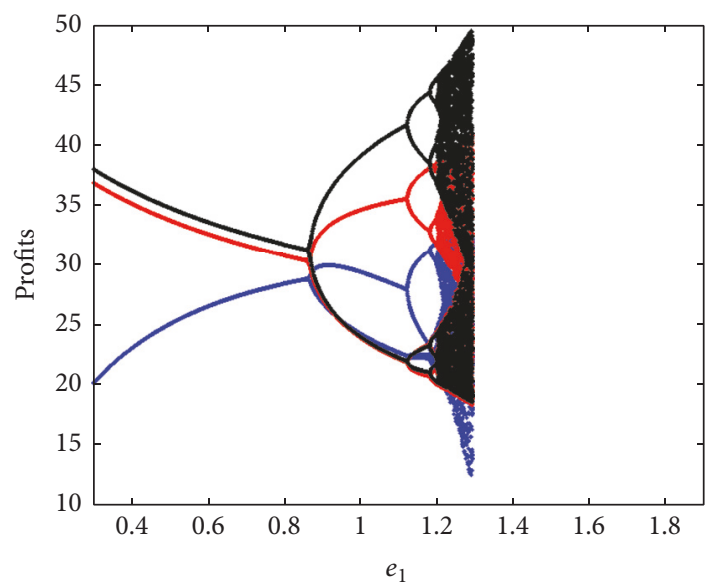

FIGURE 18: Effects of $e_{1}$ on profits, $\alpha=0.3, \beta=0.2$, and $\gamma=0.1$.

\section{Chaos Control}

According to the above numerical simulation, we can see that if the firms' price adjustment speeds are beyond the stable region, the market will lose stability and even fall into chaos.

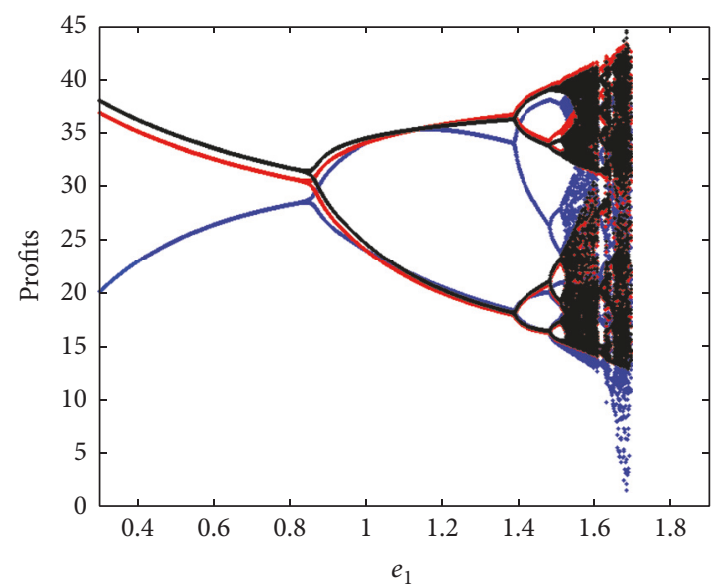

FIgURE 19: Effects of $e_{1}$ on profits, $\alpha=0.2, \beta=0.2$, and $\gamma=0.2$.

Chaos in the economic systems is harmful to all the firms. In order to avert the risk, it is expedient for prices chosen by Triopoly to maintain at Nash equilibrium.

Many methods for the chaos control have been proposed, such as time-delayed feedback method [18], modified straight-line stabilization method [19], OGY method [20], and pole placement method [21]. In this section, feedback control method proposed by Elabbasy et al. [1] is used, so the controlled system is given by

$$
\begin{gathered}
q_{1}(t+1)=q_{1}(t)+\alpha q_{1}(t) \\
{\left[e_{1}\left(a-2 b q_{1}(t)-b\left(q_{2}(t)+q_{3}(t)\right)\right)-2 c_{1} q_{1}\right]} \\
q_{2}(t+1)=q_{2}(t)+\frac{\beta}{k+1} q_{2}(t) \\
{\left[e_{2}\left(a-2 b q_{2}(t)-b\left(q_{1}(t)+q_{3}(t)\right)\right)-2 c_{2} q_{2}\right]} \\
q_{3}(t+1)=q_{3}(t)+\gamma q_{3}(t) \\
{\left[e_{3}\left(a-2 b q_{3}(t)-b\left(q_{2}(t)+q_{1}(t)\right)\right)-2 c_{3} q_{3}\right],}
\end{gathered}
$$

where $k$ is the controlling factor and the Jacobian matrix of (22) is given as

$$
J=\left(\begin{array}{ccc}
J_{1} & -\alpha b e_{1} q_{1} & -\alpha b e_{1} q_{1} \\
-\frac{\beta}{k+1} b e_{2} q_{2} & \frac{J_{2}}{k+1} & -\frac{\beta}{k+1} b e_{2} q_{2} \\
-\gamma b e_{3} q_{3} & -\gamma b e_{3} q_{3} & J_{3}
\end{array}\right),
$$

where

$$
\begin{aligned}
J_{1}= & -\alpha q_{1}\left(2 c_{1}+2 b e_{1}\right) \\
& -\alpha\left(e_{1}\left(b\left(q_{2}+q_{3}\right)-a+2 b q_{1}\right)+2 c_{1} q_{1}\right) \\
J_{2}= & -\beta q_{2}\left(2 c_{2}+2 b e_{2}\right) \\
& -\beta\left(e_{2}\left(b\left(q_{1}+q_{3}\right)-a+2 b q_{2}\right)+2 c_{2} q_{2}\right) \\
J_{3}= & -\gamma q_{3}\left(2 c_{3}+2 b e_{3}\right) \\
& -\gamma\left(e_{3}\left(b\left(q_{1}+q_{2}\right)-a+2 b q_{3}\right)+2 c_{3} q_{3}\right) .
\end{aligned}
$$




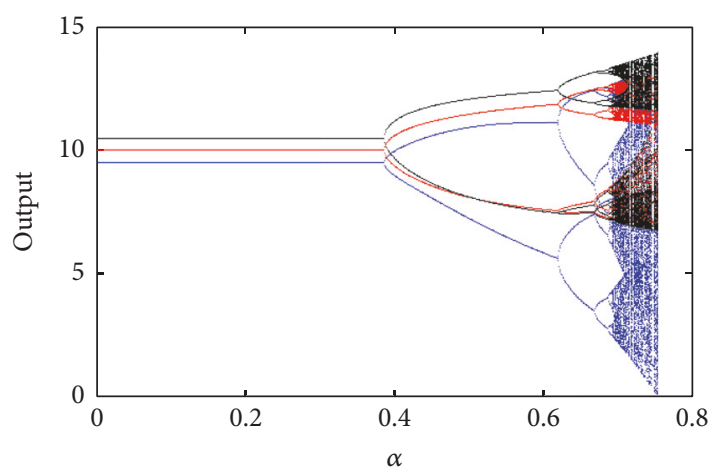

FIGURE 20: Bifurcation diagram with $\alpha, k=0.5$.

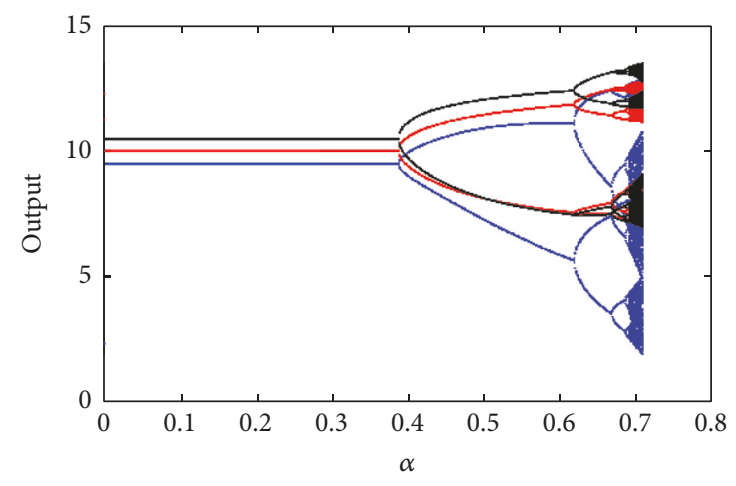

FIGURE 21: Bifurcation diagram with $\alpha, k=1$.

In the practice market, $k$ can be considered as the learning ability or adaptability of firm 2. For example, firm 2 analyzed the information in the past and adjusted the speed of price. As what can be seen from Figures 20,21, and 22, the chaos can be delayed and even eliminated with proper $k$. As for Figure 11, set $k=0.5,1,2$, respectively; we can get Figures 20-22.

As can be seen, with the increase of the control factor $k$, the emergence of bifurcation is delayed. So if the second bounded rational player adopts this adjustment method, the price game can reach equilibrium state finally.

Let $\alpha=0.35, \beta=0.2$, and $\gamma=0.2$, according to Figure 11; the system is in chaos, if $\alpha, \beta$, and $\gamma$ are fixed, and player 2 changes the controlling factor $k$; we can get the following bifurcation diagram with the controlling factor $k$. As can see from Figure 23, when $k<0.028$, the system is in a chaotic state, when $0.029 \leq k \leq 0.030$, the system is in a 16-period cycle, when $0.031 \leq k \leq 0.037$, the system is in 8 -period cycle, when $0.038 \leq k \leq 0.16$, the system is in a 4 -period cycle, when $0.16 \leq k \leq 0.76$, the system is in a 2 -period cycle state, and the system reaches equilibrium state when $k \leq 0.76$.

\section{Global Stability of the System}

In order to investigate the impact of price adjustment speed on the global stability, we introduced basins of attraction, which include attraction domain, attractor, and escaping area. Let $\left(e_{1}, e_{2}\right)=(1,1)$, and fix $q_{3}$ at $10,7,5$. We make basins of attraction with initial output $q_{1}$ and $q_{2}$.

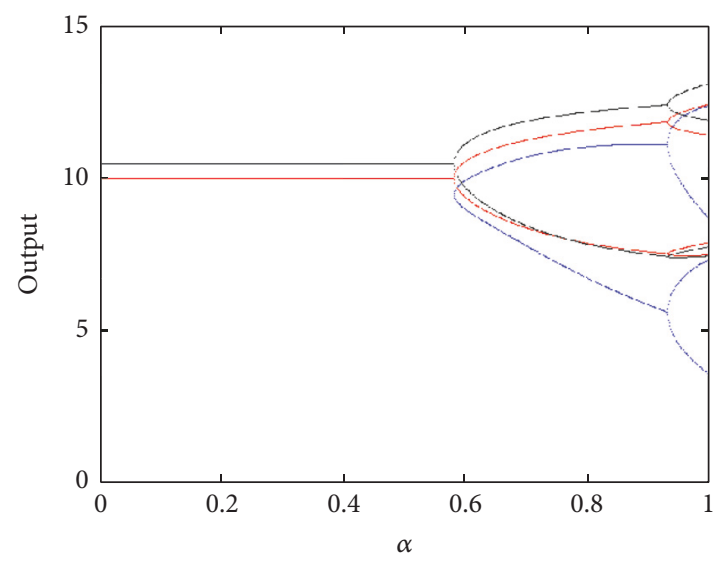

FIGURE 22: Bifurcation diagram with $\alpha, k=2$.

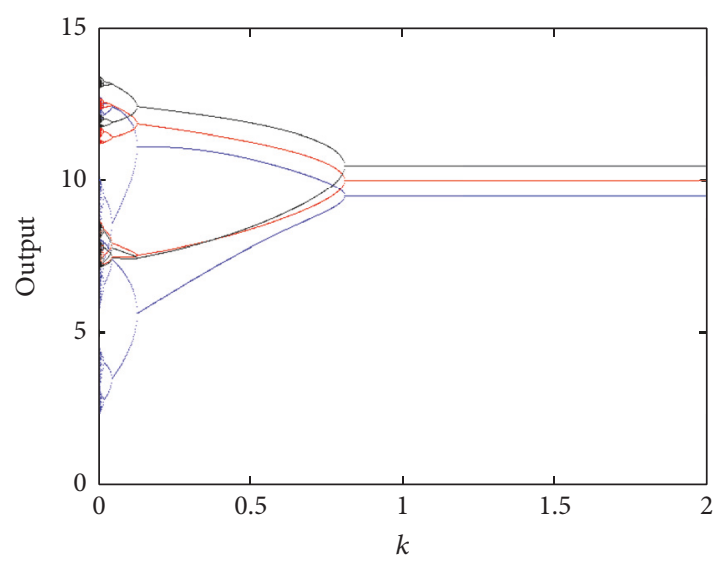

FIgURE 23: Bifurcation diagram with the controlling factor $k, \alpha=$ $0.35, \beta=0.2$, and $\gamma=0.2$.

The attraction domain is the set of initial output where the same attractor will emerge after a series of iteration if the initial price is taken from the attraction domain. As for the attractor, if it is one equilibrium point, from an economic point of view, the corresponding attraction domain will be a safe region, which means that if the initial output of two sides is in the safe region, the system will remain stable after iteration. If the initial price is in the escape area, the system will fall into divergence at last.

By fixing the system parameters as mentioned above and setting $(\alpha, \beta)=(0.3,0.1),(0.3,0.25)$, respectively, six basins of attraction about $\left(p_{1}, p_{2}\right)$ of the system are shown in Figures 24-29 in which the green region denotes attraction domain, the red set of points denotes attractor, and the blue set of points denotes escape area.

In Figure 24, when $\alpha=0.3, \beta=0.1$, and $q_{3}=10$, the system is in 2-period cycle, and we can see that the attraction domain is an irregular hexagon. In Figure 25, when $\alpha=0.3$, $\beta=0.25$, and $q_{3}=10$, the system is in period- 2 state, which means that if the initial prices of two sides are in this attraction domain, then outputs will oscillate between two points at last. The attraction domain is also an irregular pentagon area and chaotic attractor appears. In Figure 26, when $\alpha=0.3, \beta=0.1$, and $q_{3}=7$, the system is in 2-period 


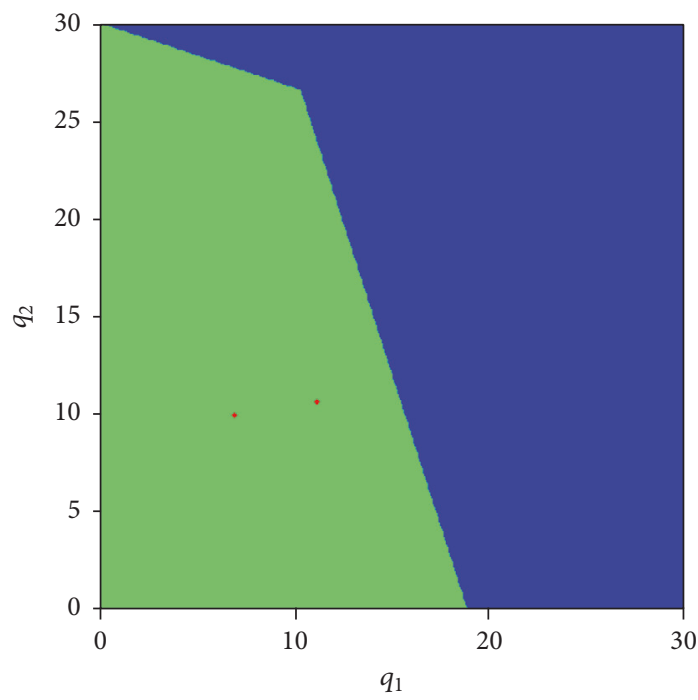

Figure 24: Basins of attraction, $\alpha=0.3, \beta=0.1$, and $q_{3}=10$.

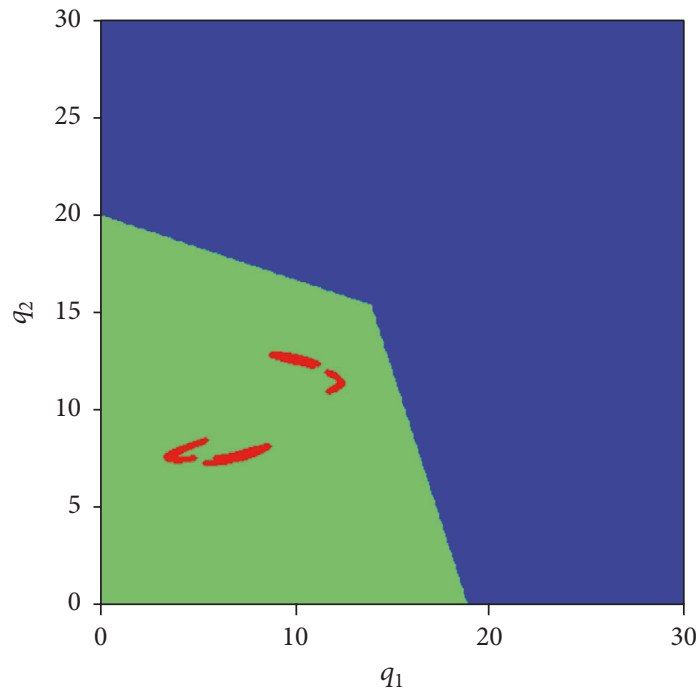

FIgURE 25: Basins of attraction, $\alpha=0.3, \beta=0.25$, and $q_{3}=10$.

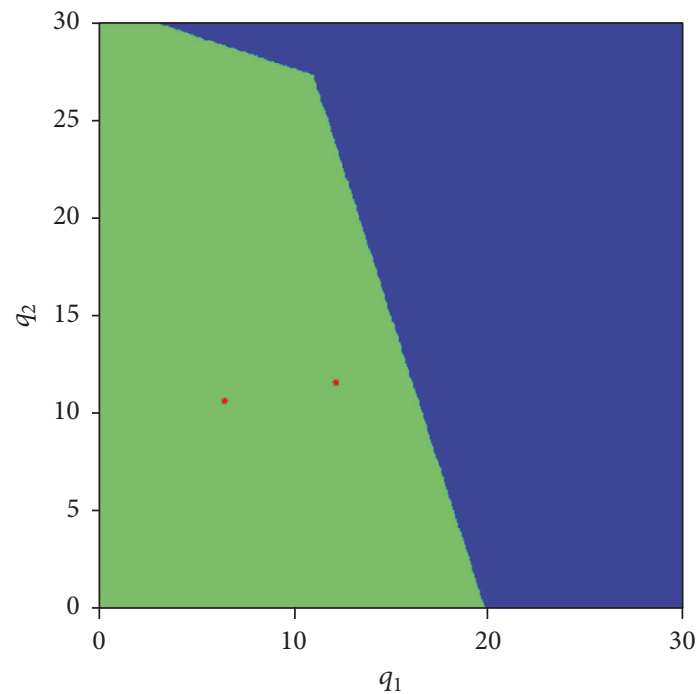

Figure 26: Basins of attraction, $\alpha=0.3, \beta=0.1$, and $q_{3}=7$.

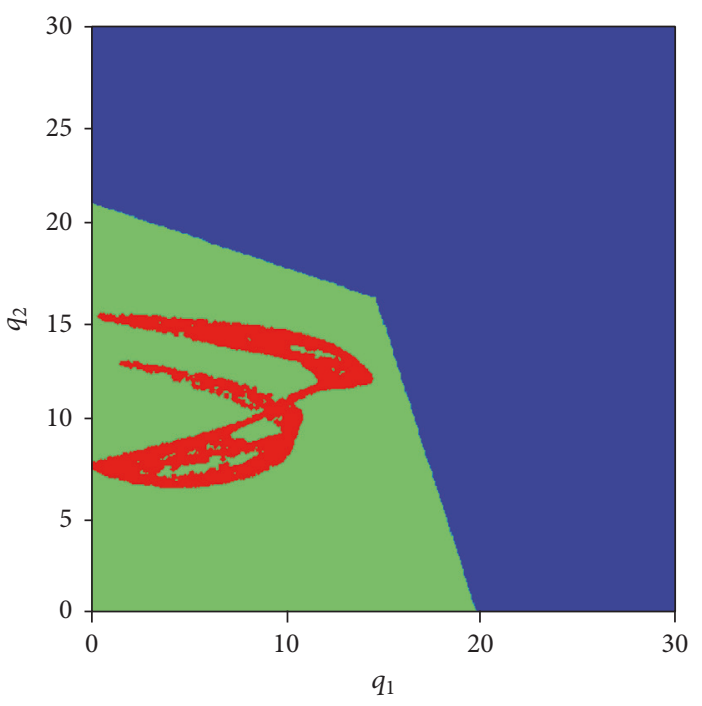

Figure 27: Basins of attraction, $\alpha=0.3, \beta=0.25$, and $q_{3}=7$.

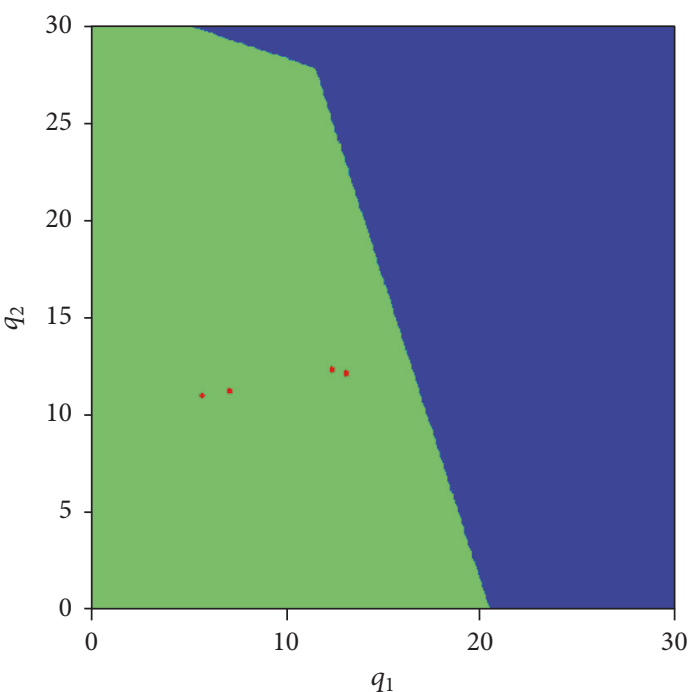

Figure 28: Basins of attraction, $\alpha=0.3, \beta=0.1$, and $q_{3}=5$.

cycle. In Figure 27, when $\alpha=0.3, \beta=0.25$, and $q_{3}=7$, the system is in chaos. In Figure 28, when $\alpha=0.3, \beta=0.1$, and $q_{3}=5$, the system is in 4-period cycle. In Figure 29, when $\alpha=0.3, \beta=0.25$, and $q_{3}=5$, the system is in chaos.

Comparing Figures $24-29$, we find that the attraction domain reduces with the increase of price modification speed. Obviously, when $\beta$ of player 2 increases, in the attraction domain, the range of $q_{2}$ reduces. We can also find that, with increase of $q_{3}$, attraction domain reduces, although not so obvious.

From an economic perspective, the initial outputs of firm 1 and 2 should be lower in order to maintain market stability.

\section{Conclusion}

In this paper, Triopoly game with inaccurate demand beliefs is considered. Suppose all the firms as bounded rationally 


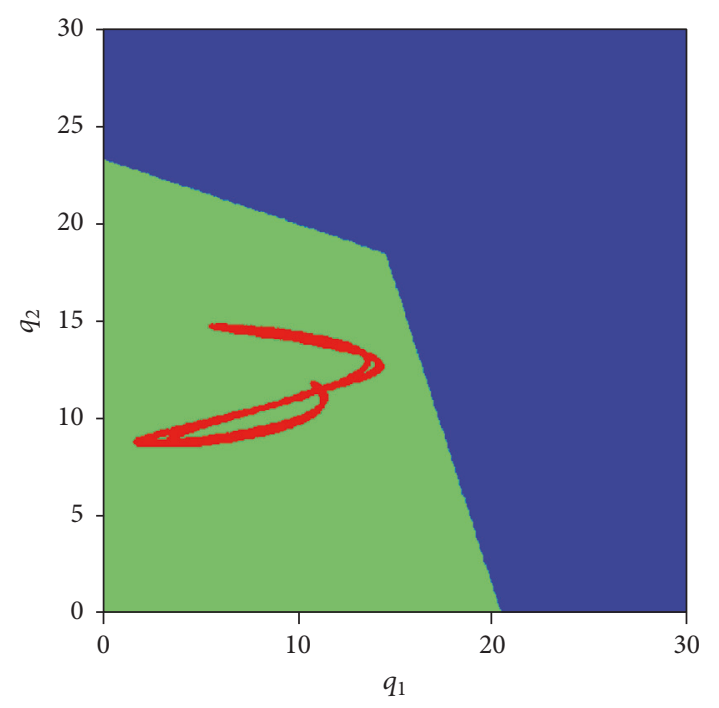

Figure 29: Basins of attraction, $\alpha=0.3, \beta=0.25$, and $q_{3}=5$.

players with demand evaluation bias. Equilibrium output is negatively related to players' costs; the value of $e_{i}$ is negatively related to range of stability.

2D bifurcation diagram is introduced and we find that with the increase of output modification speed or $e_{i}$, the system will fall into chaos via period-doubling bifurcations. Increase in $e_{1}$ will increase equilibrium output $q_{1}$ while decreasing equilibrium output of other players.

Basins of attraction are investigated and results show that if a player speeds up his own output adjustment, the output of this player in the attraction domain will become smaller. In order to maintain market stability, a firm's output must be kept within a certain range. Feedback control method is used to help the system to keep at an equilibrium state.

\section{Conflicts of Interest}

The authors declare that they have no competing financial interests.

\section{Acknowledgments}

The research was supported by the National Natural Science Foundation of China (no. 71571131) and Tianjin University Innovation Fund.

\section{References}

[1] E. M. Elabbasy, H. N. Agiza, and A. A. Elsadany, "Analysis of nonlinear triopoly game with heterogeneous players," Computers \& Mathematics with Applications, vol. 57, no. 3, pp. 488-499, 2009.

[2] J. Ma and Y. Liu, "Exact solutions for a generalized nonlinear fractional Fokker-Planck equation," Nonlinear Analysis: Real World Applications, vol. 11, no. 1, pp. 515-521, 2010.

[3] M. T. Yassen and H. N. Agiza, "Analysis of a duopoly game with delayed bounded rationality," Applied Mathematics and Computation, vol. 138, no. 2-3, pp. 387-402, 2003.
[4] J. Ma and W. Ren, "Complexity and Hopf bifurcation analysis on a kind of fractional-order IS-LM macroeconomic system," International Journal of Bifurcation and Chaos, vol. 26, no. 11, pp. 1-11, 2016.

[5] F. Tramontana and A. E. Elsadany, "Heterogeneous triopoly game with isoelastic demand function," Nonlinear Dynamics, vol. 68, no. 1-2, pp. 187-193, 2011.

[6] J.-H. Ma and W.-Z. Ji, "Complexity of repeated game model in electric power triopoly," Chaos, Solitons and Fractals, vol. 40, no. 4, pp. 1735-1740, 2009.

[7] J. Ma and K. Wu, "Complex system and influence of delayed decision on the stability of a triopoly price game model," Nonlinear Dynamics, vol. 73, no. 3, pp. 1741-1751, 2013.

[8] J. Ma and X. Pu, "The research on Cournot-Bertrand duopoly model with heterogeneous goods and its complex characteristics," Nonlinear Dynamics, vol. 72, no. 4, pp. 895-903, 2013.

[9] G.-I. Bischi, C. Chiarella, and M. Kopel, “The long run outcomes and global dynamics of a duopoly game with misspecified demand functions," International Game Theory Review, vol. 6, no. 3, pp. 343-379, 2004.

[10] H. Wang and J. Ma, "Complexity analysis of a cournotbertrand duopoly game model with limited information," Discrete Dynamics in Nature and Society, vol. 2013, Article ID 287371, 6 pages, 2013.

[11] G.-I. Bischi, L. Sbragia, and F. Szidarovszky, "Learning the demand function in a repeated cournot oligopoly game," International Journal of Systems Science, vol. 39, no. 4, pp. 403-419, 2008.

[12] Y. Guo and J. Ma, "Research on game model and complexity of retailer collecting and selling in closed-loop supply chain," Applied Mathematical Modelling, vol. 37, no. 7, pp. 5047-5058, 2013.

[13] Z. Qiu, N. Gui, and G. Deconinck, "Analysis of dynamic game played with inaccurate demand beliefs," Applied Mathematics and Computation, vol. 230, pp. 530-541, 2014.

[14] L. Sun and J. Ma, "Study and simulation on discrete dynamics of Bertrand triopoly team-game," Mathematical Problems in Engineering, vol. 2015, Article ID 960380, 12 pages, 2015.

[15] I. Manimehan and P. Philominathan, "Composite dynamical behaviors in a simple series-parallel LC circuit," Chaos, Solitons \& Fractals, vol. 45, no. 12, pp. 1501-1509, 2012.

[16] Z. Zhang, J. Wu, Y. Suo, and X. Song, “The domain of attraction for the endemic equilibrium of an SIRS epidemic model," Mathematics and Computers in Simulation, vol. 81, no. 9, pp. 16971706, 2011.

[17] J. X. Zhang, Q. L. Da, and Y. H. Wang, "Analysis of nonlinear duopoly game with heterogeneous players," Economic Modelling, vol. 24, no. 1, pp. 138-148, 2007.

[18] H. N. Agiza, "On the analysis of stability, bifurcation, chaos and chaos control of Kopel map," Chaos, Solitons \& Fractals, vol. 10, no. 11, pp. 1909-1916, 1999.

[19] J. Du, T. Huang, and Z. Sheng, "Analysis of decision-making in economic chaos control," Nonlinear Analysis. Real World Applications, vol. 10, no. 4, pp. 2493-2501, 2009.

[20] J. A. Holyst and K. Urbanowicz, "Chaos control in economical model by time-delayed feedback method," Physica A: Statistical Mechanics and its Applications, vol. 287, no. 3-4, pp. 587-598, 2000.

[21] A. Matsumoto, "Controlling the cournot-nash chaos," Journal of Optimization Theory and Applications, vol. 128, no. 2, pp. 379392, 2006. 


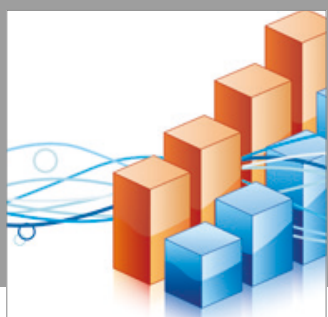

Advances in

Operations Research

vatersals

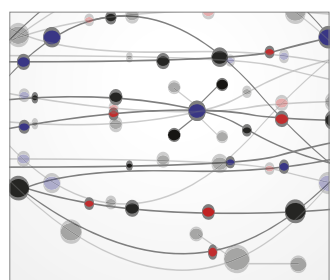

\section{The Scientific} World Journal
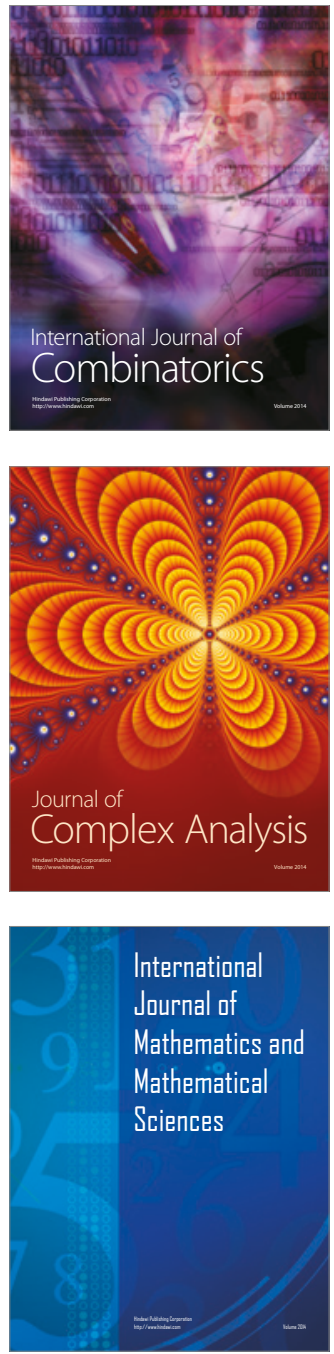
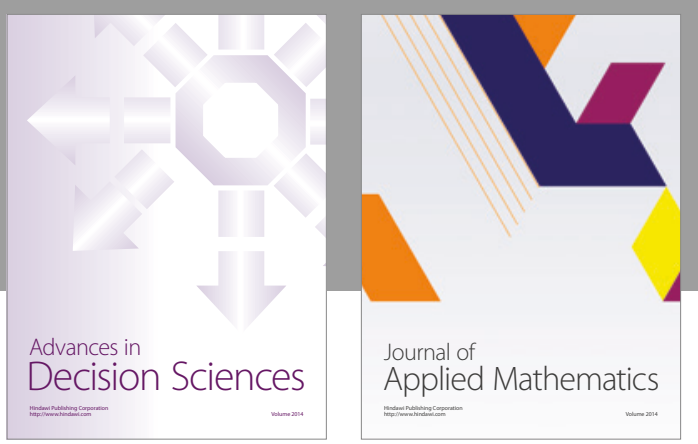

Algebra

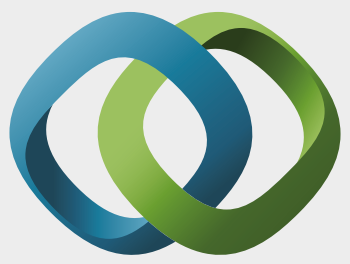

\section{Hindawi}

Submit your manuscripts at

https://www.hindawi.com
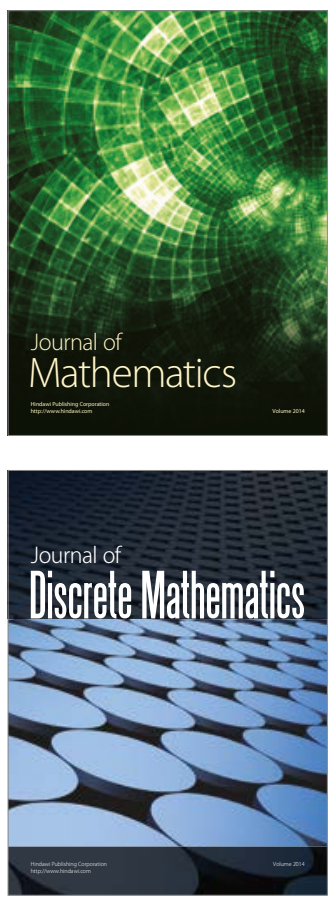

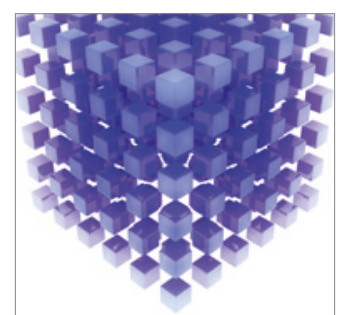

Mathematical Problems in Engineering
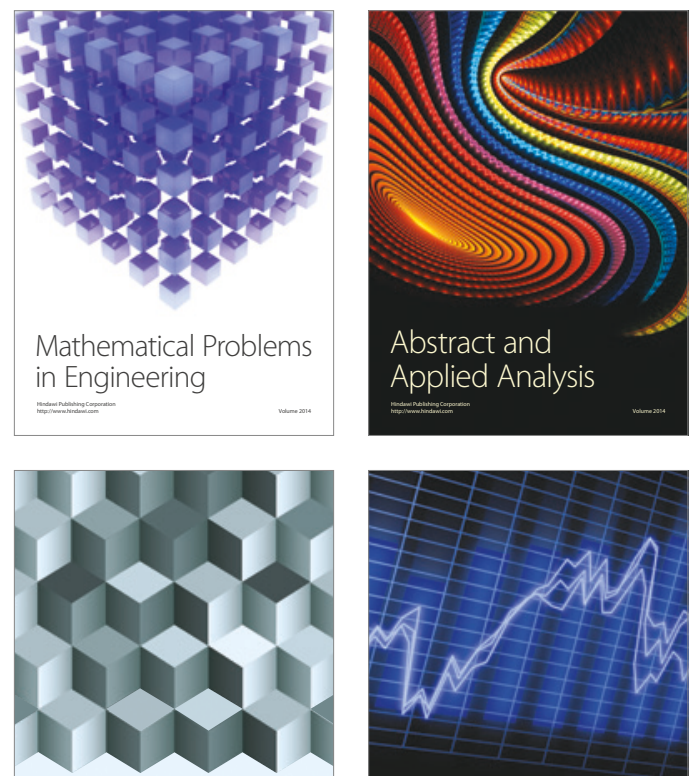

Journal of

Function Spaces

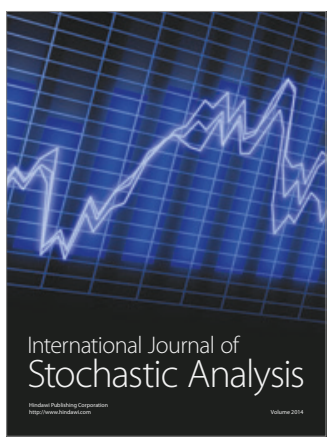

Probability and Statistics
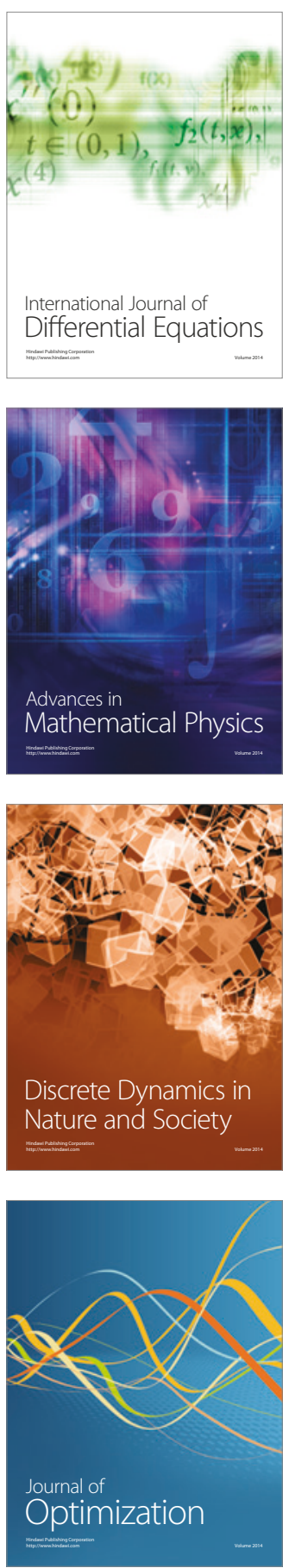